Article

\title{
Digital Tourism: An Alternative View on Cultural Intangible Heritage and Sustainability in Tavira, Portugal
}

\author{
Alexandra Rodrigues Gonçalves ${ }^{1}$ (D) Laura Lou Peres Dorsch ${ }^{2}$ and Mauro Figueiredo ${ }^{3, *}$ \\ 1 CinTurs, Research Centre for Tourism, Sustainability and Wellbeing, Universidade do Algarve, \\ 8005-139 Faro, Portugal; marodrig@ualg.pt \\ 2 iHERITAGE, Universidade do Algarve, 8005-139 Faro, Portugal; lldorsch@ualg.pt \\ 3 CIMA, Centre for Marine and Environmental Research, Universidade do Algarve, 8005-139 Faro, Portugal \\ * Correspondence: mfiguei@ualg.pt
}

check for updates

Citation: Gonçalves, A.R.; Dorsch, L.L.P.; Figueiredo, M. Digital Tourism: An Alternative View on Cultural Intangible Heritage and Sustainability in Tavira, Portugal. Sustainability 2022, 14, 2912. https:// doi.org/10.3390/su14052912

Academic Editor: Colin Michael Hall

Received: 31 January 2022

Accepted: 25 February 2022

Published: 2 March 2022

Publisher's Note: MDPI stays neutral with regard to jurisdictional claims in published maps and institutional affiliations.

Copyright: (C) 2022 by the authors. Licensee MDPI, Basel, Switzerland. This article is an open access article distributed under the terms and conditions of the Creative Commons Attribution (CC BY) license (https:// creativecommons.org/licenses/by/ $4.0 /)$.

\begin{abstract}
The digitalization of cultural routes and virtual storytelling has emerged as a way of showcasing to individuals the heritage of different cultural universes. Regarding this fractional environment, and as a by-product of the international EU funded iHERITAGE project, (B_A.2.1_0056), the goal is to create, through an innovation-driven growth process and technological transfer, brand strategies for the affirmation and better knowledge of intangible realities in the Mediterranean region. The Sicilian Tourism Department in Italy is the project's lead beneficiary, with representative partners throughout six Mediterranean countries (Italy, Egypt, Spain, Jordan, Lebanon, Portugal). The case study in Portugal is being developed in Tavira, through the intangible cultural heritage of the Mediterranean diet. The research based on the cultural experience, the history of the landscape and the sense of identity and continuity of knowledge is reassigned into a digital platform-the creation of apps and, within this, the design of a virtual route that navigates key geographical places. These apps will later revolve around one of the cultural elements of the Mediterranean, namely, the olive oil activity, with a detailed presentation of the manufacturing process, as well as its didactic interpretation and dissemination about the protection and conservation of Mediterranean research. The methodological approach is developed through the analysis and interpretation of a detailed list of references, fieldwork in a plurality of sites, contextual inquiries and interviews. As a powerful tool for internet marketing and research, these apps will reinforce identity, hospitality and tourism enterprises connected through the virtual itinerary, allowing a closer interaction between tourists and locals, endorsing the rise of technological development, as well as to drastically reduce environmental and ecological risks.
\end{abstract}

Keywords: intangible cultural heritage; tourism; augmented virtual reality; hospitality; identity Mediterranean diet; culture

\section{Introduction}

Intangible cultural heritage (ICH) is the aggregation of all immaterial manifestations of culture, the representation of the living culture of human communities, as well as the vehicle of cultural diversity [1]. The iHERITAGE: ICT Mediterranean platform for UNESCO cultural heritage (B_A.2.1_0056), follows, from a general point of view, the perception of adequate safeguarding for immaterial cultural heritage and the intensification of intercultural contacts. The project's main purpose, which emerges implicitly or explicitly from the definition just reproduced, integrates identity, hospitality, culture and tourism in sustainable strategies in social media. Through this, the ambition is to endorse better development and promotion of intangible cultural heritage ventures in an accessible and integrated way, building virtual bridges throughout the project's geographical partnership, created between six Mediterranean countries: Italy, Egypt, Spain, Jordan, Portugal and Lebanon. Portugal is being represented by the University of Algarve (UAlg), Escola 
Superior de Gestão, Hotelaria e Turismo (ESGHT), with a team of researchers, specialized in the fields of history, anthropology, tourism and tech, who aspire to give international notoriety, through a range of technological innovations for user/consumer experience, to one of the key elements of the Mediterranean Basin - the ancient Mediterranean diet. Considered by many as a lifestyle of healthy dietary patterns [2-5], the origin of the concept "Mediterranean diet" (MD) is based on the study of sustenance traditions and health benefits of the populations of Greece and Southern Italy, in the fifties and sixties of the 20 th century $[6,7]$. However, these cultures of the southern landscapes were dictated much earlier by the cycles of nature-what the land gave you, was what you ate! A relationship with the environment was deepened in order to ensure livelihoods when the climate did not help and throughout Southern Europe, Western Asia, North Africa and Australia, variations of this dietary pattern began to appear [8-11]. The broad circle that encompasses the profound depth of the Mediterranean Basin follows the themes related to sustainability, culture and heritage, ensuring the possibility of underlining emotion as the basis for recognizing unique stories and expressing them through tools that were once considered not to be exclusive to certain classical subjects. Here, the motivation of the iHERITAGEUAlg team lies in the virtual storytelling and educational data of a particular geographical place, offering a glimpse into local history and oral traditions, accessible to a broader international community.

Granted, the research idea is still on its embryonic stage, however, it assumes the capacity for a greater meaning, in which each researcher contributes with a piece to solving the puzzle-because the usage of modern technology is a necessity [12] and it has the capability to personalize information, through a multi-language functionality and attractiveness, challenging then regular usage by new modern tourists, following up with new ways to have an understanding of world heritage. Moreover, we are becoming a world of growing global consciousness [13,14] - the model of social interrelation is opened to other ways of communication and this historical change specifies a requirement to reconfigure traditional, social and cultural structures. In other words, virtual social networks have merged into a new norm where technology, information, communication, tradition, culture and history provide the compulsory system that serves both a local to global structure and a global to local framework, stimulating, in-between, the power of cultural, social and artistic diffusion. Furthermore, it seems that the dominant role of the Western world in the contemporary globalization development is perceived to be the "culture" of the global village [15] —additional to this train of thought, it is reasoned that while each of the three crises of globalization (the crisis of the environment, the crisis of the economy and the crisis of identity) are acknowledged on a global scope, they are, nevertheless, perceived locally [16]. In addition to this general perspective of things, the research on cultural heritage encompasses not only the ground-breaking reality of economic predicaments and sustainability problems, as it exposes the legacy of the applied "smart" concept to the phenomena that is tourism today [17]. The logical progression from traditional tourism to the foundation for innovations and technological orientation of the overall industry was arranged with the extensive adoption of information and communication technologies (ICT's) in tourism $[18,19]$. Naturally, this development continues with the prevalent adoption of social media by tourists and travel agents [20], recognizing technology as an infrastructure in tourism that will embrace a variety of smart computing technologies that integrate hardware, software and network expertise to optimize business processes and business performances [21], as well as to register the mobility of tourism information and of tourism consumers [22]. This is also a way to attract youngsters to cultural heritage and to better disseminate our culture.

\section{Interactive Technologies, Tourism and Intangible Cultural Heritage}

The usage of interactive technologies, such as virtual reality (VR) or augmented reality (AR), delivers a significant novelty $[23,24]$. The development of extended reality technologies [25] and mobile applications can be used as a monitor for the improvement of a 
socio-cultural experience-moreover, it is a path towards an interdisciplinary application framework, in which, advances in mobile technology have enabled a wide range of applications, morphed with the concept of augmented reality [26]. Although similar to virtual reality (VR), augmented reality (AR) is a digital technology that creates changes to an individual's perception of their physical surroundings. In other words, when viewed through a particular device, AR does not replace the real-world environment, but augments it by overlaying specific digital components. Nowadays, concerning AR applications, learning and tutoring seem to be the most explored fields of research [27-30] - following the positive effects of this technology in education, such as learning motivation, memory preservation and increased-on content [31,32], the technology also expands to the world of marketing and alternative tourism [33-35], typically working hand-in-hand with other mobile technologies, including cameras and GPS tracking, adding to the value of traveling, whilst also providing an innovative method for people to explore new places and cultures. Now, more than ever, particularly due to the COVID-19 pandemic, the prompt advancement in immersive technology is heightening the presence of extended reality in tourism [36]. Following the high contagion effect and consequential travel restrictions, social distancing, as well as regional and national lockdowns [37], the pandemic exposed the susceptibility of the tourism industry [38], which is conventionally highly dependent on individual mobility, location connectivity and destination accessibility [39]. Within the magnitude of this long and tragic period for tourism, people were forced to restructure companies, reinvent businesses and adapt an already existing "smart" meaning for tourism-in this regard, the iHERITAGE promptly follows the growth of extended reality technologies as a leading concept in the project's thematic objective, highlighting the current implementations of AR in mixed environments and the importance of digital tourism for the industry practitioners.

\section{Materials and Methods}

The research for this paper is going through a literature review that covers scientific and non-scientific publications, as well as national legislation documents [40], conventions [41-44] and inventories [45,46], concerning the safeguarding processes of intangible heritage and its engagement with the national and local community. It is important to mention that the embryonic stage of the project in UAlg has not been considered a subjectivity issue; the need to travel to Tavira makes it a necessary step in order to carry out fieldwork that is not just illustrative, further reinforcing the visits to the local community (olive oil producers, farm workers, local agro-institutions) and observing behaviors and people in their ways of life [47]. Naturally, apprehending a reality will be compulsory-the complexity of the ethnographic method is based on the contact between the ethnographer and his object of research [48,49], from which an analysis and the following categorization will be prepared, concerning the definition of ICH and the description in terms of its known five broad categories (e.g., oral traditions and expressions, performing arts, social practices, rituals and festive events, knowledge and practices concerning nature and the universe, and traditional craftsmanship). Within the process of the new currency of modern marketing landscaping, projected reality and digital art are included in cataloguing the development of local life and everyday storytelling. This documentation has the approval of the local committee and the informed consent forms from the project's participants.

Regarding the plurality of the terrain, the sites studied are interconnected in such a way that the relationships between them are as important as the relationships within them [50]. Places in space are not a mere collection of units, there must be a homogeneity and identity that reveals the joint study of these cultural geographical points [51]. Thus, as the ethnographic methodology used turns attention to a set of places, it does not necessarily mean that this confrontation and comparison determines the status of a site as unique and exclusive-a pluriactivity on the ground - and a collective of sites. Direct involvement in the community also allows for a deeper knowledge of the reality of the terrain, with regard to the debate between tourism, heritage and culture. So far, the fieldwork's experience has proven to be an experience whose diversity is, at times, laborious due to the very 
eclecticism of the practice and the rupture with rigid institutional conventions that are too formal. Nevertheless, the tourism-culture relationship follows an orientation present in the businesses and tourist attractions of the municipality under research and, therefore, to the creation of contents and interpretation of the research in situ-formalization of contacts with various local actors, from official institutions to participants in the municipality (research agreements-RA). Another method was implemented through a memorandum of understanding (MOU) between the (1) Rede de Museus do Algarve and (2) Museu Zer0. These bilateral agreements aim to (1) provide images; data collections, in terms of inventory; and recording and documentation methodologies instigated by the workinggroup RMA-PCI, on the topic of intangible cultural heritage of the Algarve. It also (2) accepts the emergence of a collaborative network for the development of artistic and marketing communication solutions, creating synergies between the curricular units and courses of the University of Algarve, as well as cooperating in the development of the Center for Experimentation and Artistic Creation at the Museu Zer0. In addition, iHERITAGE will help with the organization of joint artistic events, thus enhancing the visibility of the artistic modules created in augmented and virtual reality that value the theme of the Mediterranean, always disclosing the source and credits of all information provided.

Living labs will also be a part of the methodology approach. These events will introduce to the community the development and functionality of two mobile applications, inserted in the research architecture of the iHERITAGE project in Portugal based on the Mediterranean diet. The purpose will be to offer the local community (e.g., public and private development enterprises, stakeholders) and tourists a unique cultural experience, passed from generation to generation: from the environment and connection with nature to the importance of gastronomy, the history of landscapes and the sense of identity and continuity in the Algarve, thus provoking a necessary debate in the development of critical thinking in the local and global community.

\section{AR Intangible Heritage: The Mediterranean Diet}

The outline of a profound connection to the land over generations built the foundation of research based on innovative processes in marketing and technology transfer of AR tools, digital experiences and virtual storytelling. As part of the iHERITAGE project (B_A.2.1_0056), with the support of the Research Center for Tourism, Sustainability and Wellbeing (CinTurs) of the University of Algarve (UAlg), the digitalization of cultural routes for the affirmation and better knowledge of the Mediterranean reality of the region has allowed innovation in the traditional narratives and the improvement of the experience of those who live and practice the Mediterranean diet, recognized by UNESCO in 2010 as Intangible Cultural Heritage of Humanity. The case study in Portugal is being developed in the Algarve, in Tavira, since it has been the distinctive MD representative since 2013 [52]. At this point, the debate highlights tourism and its relationship with the "intangible cultural heritage" - the practices, representations, expressions, knowledge, skills—as well as the instruments, objects, artefacts and cultural spaces associated with them and the innovative solutions and practices implemented in the local community and in the flow of tourists. The case study in question is based on the investigation of cultural experience, transmitted from generation to generation, in response to the environment, interaction with nature, the history of the landscape and the sense of identity and continuity of knowledge. Here, the research revolves around the entire process inherent to the olive growing activity, whose fieldwork highlights the detailed presentation of the olive oil manufacturing process and the functionality in the production chain, as well as its didactic interpretation and dissemination about the protection and conservation of historical Mediterranean research.

\subsection{Augmentated Reality Applications}

Leading towards a smarter and more sustainable model (environmental, territorial and socioeconomic) is the future of tourism. Digital content is already a steady supplement to everyday life and augmented reality applications (AR apps) are an innovative platform, 
coincidently essential through consumption, utility and marketing [53]. The possibilities are endless and there are already several organizations that are offering their services around this technology to carry out virtual tours around restaurants, museums, galleries and even houses while visiting a city. The most collective examples of this engaging format of enhancing the users' surrounding real world with virtual information include (1) Pokémon Go-where users can interact with Pokémon in real time and real locations, capture them and even battle other users, all through their smartphone camera-or even more commonly used, (2) Instagram and (3) Snapchat-in which users can enhance their photographs with filters or boost their videos with virtual items or entities. With tourism, a number of applications have been developed based on the available frameworks and toolkits, all designed specifically for tourism purposes-for example, Tuscany+, a guided excursion for the Tuscany region by Fondazione Sistema Toscana [54] in Italy; Mcrumbs, the AR guide for Basel in Switzerland [55]; or perhaps, Wallkz for the Singapore Heritage Walking AR tours [56]. These enhanced, interactive and highly dynamic experiences can provide personalized information and services tailored to tourists and citizens' particular needs, inspiring the foundation for the methodological approach of the UAlg's iHERITAGE team in the structural proposal of regional cultural heritage in free augmented reality functionality.

\subsection{Foundations for a "Smart" Structural Design: Case-Study "MED DIET"}

Generally, applications are accessed over mobile devices with GPS tracking, giving the user the possibility to gain additional benefits and navigate interactively with the help of observations of particular locations. Moreover, the data within an AR application are structured and distributed through the use of various multimedia formats (sound, image, video, 3D models and hyperlinks) that can steer the route of the user outside the application [57]. The case study at hand circles two applications, MARINADE and REMIND - free interactive multimedia guides, featuring photos, audio and explanations of geo-localization. The apps will be self-contained once downloaded and will not require Wi-Fi or data connection to ensure their exploratory and informational features. In order to activate a "cross border" experience, regarding the innovative solutions achieved as the result of Research Agreements within the international iHERITAGE project, UAlg recognized the need to create partnerships within the scope of the territorial cooperation and proper instalment of the application's virtual settings. Through the management of workflows within the digital scenery, the elimination of repetitive tasks and improvement of service levels, the centralized and effective management of all documentation related to the Mediterranean diet internal process, improvement of the speed, efficiency and security of access to information of possible guided routes, as well as the classification and filing of data according to UAlg's adopted rules, the template will align the virtual exhibition of the olive press heritage manifestation (objective component) to the community of people (subjective or social component) and to the cultural space (spatial component).

- Marinade App - the aim is centered on sending png or jpeg image files, mov or mp4 video files and/or mp3 sound files and will be available on Apple and Google Store for free. Through this functionality, the app will reveal the products of the Mediterranean diet, display all information regarding the material or immaterial framework of the respective products, as well as clarification of the geographic context in question and images and videos related to traditional events and festivals that occurred or are related to the point of interest.

- Remind App-it will be available for Windows and OSX and will drive content creation for the MARINADE application. The app will associate content to geospatial positions or QR codes, upload png image files, jpeg, mov or mp4 video files and/or sound files, as well as the possibility of creating services, in order to allow other entities (companies, public services) to expand the platform and the academic context in which it was created.

As mentioned, the aim will be to offer a part of the classical Mediterranean olive press antiquity combined with AR technology - the availability of multimedia and design of the 
mobile applications will allow users to create catalogues and inventories of their favorite points of interest (POIs). Furthermore, geo-localization and AR tags throughout the usage of the apps will trigger the delivery of audiovisual support, providing further embedded information about a certain object/place, shared experiences and connectivity between the AR applications and users. Apart from the obvious benefits to app users (tourists and locals) concerning direct updates and the exchange of information and tips, the apps can function as a complementary guide to a route that delivers specific historical facts upon request, consequently reducing the effect of information overload, particularly information considered to be irrelevant or redundant [58]. Regarding the research agreements, AR applied to the Med diet will take advantage of the distinctive characteristics of mobile devices, offering the possibility for social interaction among app users through the exchange of daily activities and planning of experiences, following the trail of nutritional facts, food science and palatability in local gastronomy, as well as art events or even some workshops.

\subsection{MED DIET Digital Route}

From a general perspective, data collection and the creation of a digital route allows the iHERITAGE team to understand the breadth of cultural tourism in Tavira, to better recognize the factors that determine the extension of the intangible heritage and the policies and structures that contribute to the "territorialization" of the places researched. As the iHERITAGE project is a strategic reference on the international and academic agenda, UAlg is creating the necessary synergies for the conservation of research in the field of the Med diet, its relationship with the chosen geographic location and the analysis of the virtual route that collects the points of interest of the olive industry and the fruits' journey from the mountains to the sea. Research has proven that the virtual experience in the landscape of cultural information and cultural routes has a potentially new and important role to play [59] - the Med diet route and the virtual nature of the project associates a unique and authentic feature to the creative aspect, with the possibility of covering this idea with motifs that reinforce the ties of a shared heritage. Furthermore, authenticity in smart tourism is a truthful and genuine experience rather than a forged practice in the context of physical objects [60]. Individuals are the heart of tourism success and without experiences, services and products that offer a modern quest for authenticity, tourists cannot seek escape and allow a fully entertained immersion. Moreover, in this digital era, the possibility to engage actively in culture through a more memorable experience has users converted into dynamic actors rather than passive consumers [61,62]. The virtual route will offer a controlled digital system employed to implement the project's components, thus providing a maintainable and manageable structure. The route will approach sites and objects, integrating projection technologies into everyday activities of tourists and visitors, naturally depending on location, weather and time, all of which integrate aspects of research and fieldwork to be developed and achieved in the best possible way. The architecture and the application of the AR component in the Med diet route will have an unobtrusive interface to interact with one's surroundings and, in particular, with smart devices, thus broadening the potential market, always respecting the art of storytelling and what related challenges and issues may appear.

\section{Conclusions}

Following the discussion on AR tools, mobile devices and the successful realization of smart tourism, there are key research areas to be addressed, recognizing that this exploratory research is still in progress. The first one concerns privacy and the digital footprint left by app users-while location-based services are extremely useful, they also display the consumer's vulnerability and the opportunities for mining the digital traces left while traveling are multiple. Data capture linked to smart tourism raises big issues regarding information governance and correctly deriving the value of information [63] and there is a need for better research in the context of safety and security, whilst determining the openness and universal nature of operative applications in smart tourism. The second 
area of research to be addressed concerns technology mediation. The expenses of data from info-structures that are captured and stored have not been calculated, following assessment concerns over sustainability costs (e.g., energy consumption and e-waste) [64]. Moreover, the common features of AR methods, concerning, for example, visualization of cultural spaces and the contextualization of information, have clear implications for those who cannot afford smart tourism info-structures [65]. ICT dependence reveals concerns in three other aspects: data overload, innovation deficiencies [66] and an individual's increased desire to escape technology when on vacation. The third area implies the issue of human resources and artificial intelligence. While tourism can feed on healthy collaborations amongst various social entities, it is not a sector that entices knowledge workers and the iHERITAGE team has inferred the same conclusion. The fourth and final area falls upon the value creation opportunities supplied by smart tourism and the fair translation into working ICT's. Through the iHERITAGE project, one can acknowledge the early stage of the development of the proposed apps, hence the growing enquiry; nevertheless, one of the biggest challenges is obtaining already developed content-writing scripts and visual data-about the resources to be included in the MED DIET digital route. Moreover, the iHERITAGE team has also encountered digital access limitations at some of the geographical sites due to the lack of signalization and adequate geo-mapping information, generating difficulties in integrating identifiable movable and immovable assets. Besides all the positive aspects identified through opportunities of digital tourism to reduce negative impacts to culturally sensitive sites, one of the emerging questions identified by research is the proliferation of apps offering different services, which most people download to their mobile devices, and the lack of integration of information related to tourism destinations. Additional remarks can result from the difficulties in choosing interesting narratives that are able to keep visitors interested and make the digital experience memorable. Naturally, the lack of effective engagement is high, with extensive flaws in the mobile applications platforms that need to be seized before offering them to the public. Although many tourists are supporters of the traditional source for tourist destination information, AR displays high potential in becoming a main-stream technological tool in tourism, whether for indoor or outdoor environments $[67,68]$. Moreover, following the overview of the basic assumptions underlying the iHERITAGE concept on tourism, augmented reality tools and the smart ecosystem supported by layers of data creation, digital visualization and exchange of storytelling and experiences, this paper presented the canvas for the idea of creating a digital outline of research based on innovative processes in marketing and extended reality technologies [69]. The aim is to create two mobile applications (MARINADE and REMIND) and use them to monitor the improvement of socio-cultural experiences. Through these, transcultural subjects, such as sustainability and heritage, will be featured and recognizable through unique stories of rural Tavira, the history of olive oil and how urban areas are highlighting the Mediterranean diet in contemporary issues. The management of the two apps will follow the creation of a digital cultural route, as it will allow a closer interaction between tourists and locals, following the users' perspectives (e.g., travel experiences, impressions, emotions, special moments and opinions). These routes will be used by hospitality and tourism enterprises in certain social media platforms to promote services and reinforce identity, as well as hospitality, defining them an online reputation, disclosed to a potential tourist, anywhere and anytime.

Author Contributions: Conceptualization and methodology, A.R.G., L.L.P.D. and M.F.; software, M.F.; validation, A.R.G. and L.L.P.D.; formal analysis, A.R.G. and L.L.P.D.; investigation, L.L.P.D. and M.F.; resources, iHERITAGE; data curation, A.R.G. and L.L.P.D.; writing —original draft preparation, L.L.P.D.; writing—review and editing, L.L.P.D.; supervision, A.R.G.; project administration, A.R.G.CinTurs-UAlg; funding acquisition, iHERITAGE. All authors have read and agreed to the published version of the manuscript.

Funding: This research was funded by ENPI CBCMED, grant number B_A.2.1_0056-iHERITAGE https://www.enicbcmed.eu/projects/iheritage (accessed on 30 January 2022). 


\section{Institutional Review Board Statement: Not applicable.}

Informed Consent Statement: Not applicable.

Conflicts of Interest: The authors declare no conflict of interest.

\section{References}

1. Lenzerini, F. Intangible cultural heritage: The living culture of peoples. Eur. J. Int. Law 2011, 22, 101-120. [CrossRef]

2. Trichopoulou, A.; Lagiou, P. Healthy traditional Mediterranean diet: An expression of culture, history, and lifestyle. Nutr. Rev. 1997, 55, 383-389. [CrossRef] [PubMed]

3. Knoops, K.T.; de Groot, L.C.; Kromhout, D.; Perrin, A.E.; Moreiras-Varela, O.; Menotti, A.; Van Staveren, W.A. Mediterranean diet, lifestyle factors, and 10-year mortality in elderly European men and women: The HALE project. JAMA 2004, 292, 1433-1439. [CrossRef] [PubMed]

4. Yannakoulia, M.; Kontogianni, M.; Scarmeas, N. Cognitive health and Mediterranean diet: Just diet or lifestyle pattern? Ageing Res. Rev. 2015, 20, 74-78. [CrossRef] [PubMed]

5. Diolintzi, A.; Panagiotakos, D.B.; Sidossis, L.S. From Mediterranean diet to Mediterranean lifestyle: A narrative review. Public Health Nutr. 2019, 22, 2703-2713. [CrossRef]

6. Keys, A.B.; Keys, M. How to Eat Well and Stay Well, the Mediterranean Way; Doubleday: New York, NY, USA, 1975.

7. Keys, A.; Menotti, A.; Aravanis, C.; Blackburn, H.; Djordevic, B.S.; Buzina, R.; Dontas, A.S.; Fidanza, F.; Karvonen, M.J.; Kimura, N. The seven countries study: 2289 deaths in 15 years. Prev. Med. 1984, 13, 141-154. [CrossRef]

8. Braudel, F. Il Mediterraneo. Lo Spazio, la Storia, Gli Uomini e le Tradizioni; Bompiani: Milan, Italy, 1987.

9. Capatti, A.; Montanari, M. Italian Cuisine: A Cultural History; Columbia University Press: New York, NY, USA, 2003 ; p. 106.

10. Trichopoulou, A.; Martínez-González, M.A.; Tong, T.Y.; Forouhi, N.G.; Khandelwal, S.; Prabhakaran, D.; de Lorgeril, M. Definitions and potential health benefits of the Mediterranean diet: Views from experts around the world. BMC Med. 2014, 12,1-16. [CrossRef]

11. Arnett, D.K.; Blumenthal, R.S.; Albert, M.A.; Buroker, A.B.; Goldberger, Z.D.; Hahn, E.J.; Himmelfarb, C.D.; Khera, A.; LloydJones, D.; McEvoy, J.W.; et al. 2019 ACC/AHA Guideline on the Primary Prevention of Cardiovascular Disease. Circulation 2019, 140, e596-e646. [CrossRef]

12. Han, D.I.; Jung, T.; Gibson, A. Dublin AR: Implementing augmented reality in tourism. In Information and Communication Technologies in Tourism 2014; Springer: Cham, Switzerland, 2013; pp. 511-523.

13. Pagán, A.E. Fundamentos para la gestión del patrimonio cultural. In El Desarrollo Territorial Valenciano: Reflexiones en Torno a Sus Claves; Universitat de València: València, Spain, 2014.

14. De Tapol, B. La necesaria adaptación de la conservación preventiva al concepto de sostenibilidad con especial atención a las herramientas de gestión. Patrim. Cult. Esp. 2013, 7, 81-90.

15. Dorsch, L.L.P. Suffering Deadlock in the Arctic's Ecology and Health: The Sámi World. Ph.D. Thesis, Universidade de Lisboa, Instituto de Ciências Sociais, Lisboa, Portugal, 2021.

16. Eriken, A. The Three Crises of Globalisation: An Anthropological History of the Early 21st Century; European Commission: Brussels, Belgium, 2016.

17. Gretzel, U.; Sigala, M.; Xiang, Z.; Koo, C. Smart tourism: Foundations and developments. Electron. Mark. 2015, 25, 179-188. [CrossRef]

18. Law, R.; Buhalis, D.; Cobanoglu, C. Progress on information and communication technologies in hospitality and tourism. Int. J. Contemp. Hosp. Manag. 2014, 26, 727-750. [CrossRef]

19. Koo, C.; Gretzel, U.; Hunter, W.C.; Chung, N. The role of IT in tourism. Asia Pac. J. Inf. Syst. 2015, 25, 99-104.

20. Abou-Shouk, M.A.; Hewedi, M.M. Antecedents and consequences of social media adoption in travel and tourism: Evidence from customers and industry. Int. J. Soc. Behav. Educ. Econ. Bus. Ind. Eng. 2016, 10, 652-659.

21. Washburn, D.; Sindhu, U.; Balaouras, S.; Dines, R.A.; Hayes, N.; Nelson, L.E. Helping CIOs understand "smart city" initiatives. Growth 2009, 17, 1-7.

22. Wang, D.; Xiang, Z. The new landscape of travel: A comprehensive analysis of smartphone apps. In Information and Communication Technologies in Tourism; Fuchs, M., Ricci, F., Cantoni, L., Eds.; Springer: Wien, Austria, 2012; pp. 308-319.

23. Portalés, C.; Casas, S.; Alonso-Monasterio, P.; Viñals, M.J. Multi-dimensional acquisition, representation, and interaction of cultural heritage tangible assets: An insight on tourism applications. In Handbook of Research on Technological Developments for Cultural Heritage and Etourism Applications; IGI Global: Hershey, PA, USA, 2018; pp. 72-95.

24. Portalés, C.; Rodrigues, J.M.; Gonçalves, A.R.; Alba, E.; Sebastián, J. Digital cultural heritage. Multimodal Technol. Interact. 2018, 2, 58. [CrossRef]

25. Kwok, A.O.; Koh, S.G. COVID-19 and extended reality (XR). Curr. Issues Tour. 2021, 24, 1935-1940. [CrossRef]

26. Milgram, P.; Kishino, F. A taxonomy of mixed reality visual displays. IEICE Trans. Inform. Syst. 1994, 77, 1321-1329.

27. Stovel, H. Monitoring world heritage. In World Heritage Centre and ICCROM.; Rome (World Heritage Paper No. 10); UNESCO World Heritage Centre and ICCROM: Paris, France, 2004.

28. Bacca, J.; Baldiris, S.; Fabregat, R.; Graf, S. Augmented reality trends in education: A systematic review of research and applications. J. Educ. Technol. Soc. 2014, 17, 133. 
29. Akçayır, M.; Akçayır, G. Advantages and challenges associated with augmented reality for education: A systematic review of the literature. Educ. Res. Rev. 2017, 20,1-11. [CrossRef]

30. Cipresso, P.; Giglioli, I.A.C.; Raya, M.A.; Riva, G. The past, present, and future of virtual and augmented reality research: A network and cluster analysis of the literature. Front. Psychol. 2018, 9, 2086. [CrossRef]

31. Radu, I. Why should my students use AR? A comparative review of the educational impacts of augmented-reality. In Proceedings of the 2012 IEEE International Symposium on Mixed and Augmented Reality (ISMAR), Atlanta, GA, USA, 5-8 November 2012; pp. 313-314.

32. Radu, I. Augmented reality in education: A meta-review and cross-media analysis. Pers. Ubiquitous Comput. 2014, 18, 1533-1543. [CrossRef]

33. Ramos, C.M.; Henriques, C.; Lanquar, R. Augmented reality for smart tourism in religious heritage itineraries: Tourism experiences in the technological age. In Handbook of Research on Human-Computer Interfaces, Developments, and Applications; IGI Global: Hershey, PA, USA, 2016; pp. 245-272.

34. Chiao, H.M.; Chen, Y.L.; Huang, W.H. Examining the usability of an online virtual tour-guiding platform for cultural tourism education. J. Hosp. Leis. Sport Tour. Educ. 2018, 23, 29-38. [CrossRef]

35. Tsai, T.H.; Chen, C.M. Evaluating tourists' preferences for attributes of thematic itineraries: Holy folklore statue in Kinmen. Tour. Manag. Perspect. 2019, 30, 208-219. [CrossRef]

36. Haywood, K.M. A post COVID-19 future-tourism re-imagined and re-enabled. Tour. Geogr. 2020, 22, 599-609. [CrossRef]

37. UNWTO. Impact Assessment of the COVID-19 Outbreak on International Tourism; UNWTO: Madrid, Spain, 2020.

38. Gössling, S.; Scott, D.; Hall, C.M. Pandemics, tourism and global change: A rapid assessment of COVID-19. J. Sustain. Tour. 2020, 29, 1-20. [CrossRef]

39. Coles, T.; Hall, M. The geography of tourism is dead. Long live geographies of tourism and mobility. Curr. Issues Tour. 2006, 9, 289-292. [CrossRef]

40. Decreto-Lei No. 149/2015, de 4 de Agosto-Estabelece o Regime Jurídico de Salvaguarda do Património Imaterial in Direcção-Geral do Património Cultural. Legislação Sobre Património. Available online: http:/ /www.patrimoniocultural.gov.pt/pt/patrimonio/ legislacao-sobre-patrimonio/ (accessed on 22 January 2022).

41. Direcção-Geral do Património Cultural. Património Imaterial. Available online: http://patrimoniocultural.gov.pt/pt/ (accessed on 22 January 2022).

42. Algarve Imaterial. Património Cultural Imaterial do Algarve-Mapeamento. Available online: https: / algarveimaterial.wordpress. $\mathrm{com} /$ (accessed on 22 January 2022).

43. Costa, P.; Isnart, C. Atas do Colóquio Internacional "Políticas Públicas Para o Património Imaterial na Europa do Sul: Percursos, Concretização e Perspectivas"; Direção Geral do Património Cultural: Lisboa, Portugal, 2013; p. 2.

44. UNESCO, ICH. Basic Texts of the 2003 Convention for the Safeguarding of the Intangible Cultural Heritage; UNESCO: Paris, France, 2020.

45. Matriz PCI-Inventário Nacional de Património Cultural Imaterial. Available online: http://www.matrizpci.dgpc.pt/matrizpci. web (accessed on 22 January 2022).

46. Rede de Museus do Algarve. RMA-PCI. Available online: https://museusdoalgarve.wordpress.com/grupos-de-trabalho/rmapci/ (accessed on 22 January 2022).

47. Wittel, A. Ethnography on the move: From field to net to internet. Forum Qual. Soz./Forum Qual. Soc. Res. 2000, 86. [CrossRef]

48. Duranti, A. Husserl, intersubjectivity and anthropology. Anthropol. Theory 2010, 10, 16-35. [CrossRef]

49. Jackson, M. Essays in Existential Anthropology; University of Chicago Press: Chicago, IL, USA, 2013.

50. Hannerz, U. Being there ... and there ... and there! Reflections on multi-site ethnography. Ethnography 2003, 4, 201-216. [CrossRef]

51. Lang, G.; Benbunan-Fich, R. The Use of Social Media in Disaster Situations: Framework and Cases. In Managing Crises and Disasters with Emerging Technologies: Advancements; IGI Global: Hershey, PA, USA, 2012; pp. 11-23.

52. Gonçalves, A. Gestão do Património Mundial e Turismo-Oportunidades e Desafios dos Modelos de Governança do Património Cultural Imaterial: O Estudo de caso da Dieta Mediterrânica no Destino Algarve". In Turismo E História: Perspetivas Sobre o Património da Humanidade no Espaço Ibero-Americano; Imprensa da Universidade de Coimbra: Caxias do Sul, Brazil, 2020; pp. 67-87.

53. Peltonen, P. Virtual-and Augmented Reality in Tourism Marketing. Bachelor's Thesis, HAMK Häme University of Applied Sciences, Hämeenlinna, Finland, 2020.

54. Fondazione_Sistema_Toscana. Tuscany+. Available online: http://www.turismo.intoscana.it/allthingstuscany/aroundtuscany/ tuscany-the-first-augmented-reality-tourism-application/ (accessed on 18 December 2021).

55. mCRUMBS. Basel Augmented Reality Tourist Guide. Available online: http://www.perey.com/AugmentedRealityForBasel/ (accessed on 18 December 2021).

56. Waalkz. Singapore Heritage Walking AR Tours. Available online: https://freshapps.com/waalkz-singapore-heritage-walkingtours / (accessed on 18 December 2021).

57. Kounavis, C.D.; Kasimati, A.E.; Zamani, E.D. Enhancing the tourism experience through mobile augmented reality: Challenges and prospects. Int. J. Eng. Bus. Manag. 2012, 4, 10. [CrossRef]

58. Oppermann, R.; Specht, M. A Nomadic Information System for Adaptive Exhibition Guidance. In Proceedings of the International Conference on Hypermedia and Interactivity in Museums, Paris, France, 3-5 September 1999; pp. 103-109. 
59. Richards, G. Tourism Trends: Tourism, Culture and Cultural Routes; Khovanova-Rubicondo, K., Ed.; Council of Europe: Strasbourg, France, 2011.

60. Gilmore, J.H.; Pine, B.J. Authenticity: What Consumers Really Want; Harvard Business Press Center: Boston, MA, USA, 2017.

61. Pine, B.J.; Gilmore, J.H. The Experience Economy; Harvard Business School Press: Boston, MA, USA, 1999.

62. Kim, M.J.; Lee, C.K.; Jung, T. Exploring consumer behavior in virtual reality tourism using an extended stimulus-organismresponse model. J. Travel Res. 2020, 59, 69-89. [CrossRef]

63. Tallon, P.P. Corporate governance of big data: Perspectives on value, risk, and cost. Computer 2013, 46, 32-38. [CrossRef]

64. Gretzel, U. Travel in the Network: Redirected Gazes, Ubiquitous Connections and New Frontiers. In Post-Global Network and Everyday Life; Levina, M., Kien, G., Eds.; Peter Lang: New York, NY, USA, 2010; pp. 41-58.

65. Minghetti, V.; Buhalis, D. Digital divide in tourism. J. Travel Res. 2010, 49, 267-281. [CrossRef]

66. Hjalager, A.M. Repairing innovation defectiveness in tourism. Tour. Manag. 2002, 23, 465-474. [CrossRef]

67. Fritz, F.; Susperregui, A.; Linaza, M.T. Enhancing cultural tourism experiences with augmented reality technologies. In Proceedings of the 6th International Symposium on Virtual Reality, Archaeology and Cultural Heritage (VAST), Pisa, Italy, 8-11 November 2005.

68. Pang, Y.; Nee, A.; Ong, S.; Yuan, M.; Youcef-Toumi, K. Assembly feature design in an augmented reality environment. Assem. Autom. 2006, 26, 34-43. [CrossRef]

69. iHERITAGE. iHERITAGE: ICT Mediterranean Platform for UNESCO Cultural Heritage. Available online: https://www. enicbcmed.eu/projects/iheritage (accessed on 22 January 2022). 